\title{
Comparison between scalar and corrected orthogonal electrocardiogram in diagnosis of acute myocardial infarcts
}

\author{
Jan Erikssen and Carsten Müller \\ From Medical Department, Central Hospital in Akershus, Lörenskog and Cardiological \\ Laboratory, Rikshospitalet, Oslo University, Oslo, Norway
}

Twelve-lead electrocardiograms and orthogonal electrocardiograms taken with Frank's corrected orthogonal lead system have been compared in 259 patients with recent myocardial infarction. In the scalar electrocardiograms a diagnostic recognition rate of 62 per cent was recorded. $Q / R-$ ratios $>0.2 I$ in $X$ lead, $>0.22$ in $Y$ lead, and $<0.10$ or $>I \cdot 20$ in $Z$ lead were used as signs of myocardial infarction in the orthogonal electrocardiograms. Eighty-two per cent showed pathological $Q / R$ ratios according to these criteria. The orthogonal electrocardiogram technique is of value in the diagnosis of recent myocardial infarction because of its simplicity, the strict criteria which can be applied, and the high recognition rate.

Alone or in combination with other tests, the electrocardiogram provides the best diagnostic criteria of recent myocardial infarction. From a theoretical point of view, however, it is not possible to diagnose all cases of recent myocardial infarction from the electrocardiogram. The aim of this study was to compare the diagnostic changes in the I2-lead electrocardiograms according to accepted criteria with orthogonal electrocardiograms hoping to improve accuracy in the diagnosis of myocardial infarction.

\section{Material and methods}

The material comprises all patients with the diagnosis of recent myocardial infarction seen during a period of one year provided the case history was less than 48 hours and the patients had lived more than 24 hours after admission to the hospital. The diagnoses were based on case histories, electrocardiograms, and SGOT values. In all patients at least one orthogonal electrocardiogram was also taken. Twelve lead electrocardiograms and SGOT levels were recorded on the first, second, and third days after admission and just before discharge and further electrocardiograms were usually recorded during the stay. Orthogonal electrocardiograms were recorded on the second and third days and just before the patients left hospital, using Frank's corrected orthogonal lead system (Frank, 1956). All the electrocardiograms were taken with a Mingograph ECG analyser. Pathological $Q$ waves in the scalar electrocardiograms were taken as a sign of myocardial infarction Received 25 February 1971. according to accepted criteria (Lipman and Massie, 1965). Electrocardiograms with pathological $Q$ waves were termed 'typical' and those without pathological $Q$ waves 'atypical'. Cases with bundle-branch block were regarded as typical provided there was at least one electrocardiogram with normal conduction showing a typical $Q$ wave pattern of myocardial infarction, as also were cases of right bundle-branch block with signs of anterior or diaphragmatic myocardial infarction. The ST and $T$ wave changes were regarded as primary abnormalities as not according to the ventricular gradient approach of Grant (I957). In all patients at least one transaminase value exceeded 40 Karmen units. All cases with border-line SGOT values showed a definite peak value of the SGOT during one of the first few days, with normalization later. Case histories with pain in the upper abdomen, in the chest, and/or in the front of the neck have been called typical case histories, while case histories without pain have been called atypical. All patients with atypical case histories had typical I2-lead electrocardiograms except 6 patients in whom there were borderline I2-lead electrocardiograms with distinctly pathological orthogonal curves.

Increase of erythrocyte sedimentation rate to at least $10 \mathrm{~mm} / \mathrm{hour}$ from the first to the fifth day in the hospital has been called positive erythrocyte sedimentation rate reaction. A temperature of $38^{\circ} \mathrm{C}$ or more during the first four days has been called a positive temperature reaction, while a maximum temperature less than $38^{\circ} \mathrm{C}$ has been called a negative temperature reaction (despite the fact that many of these patients had a subfebrile reaction, followed by normal temperature in a few days). Earlier angina pectoris has been defined 
as typical chest pain provoked by physical and/or emotional stress for at least one month before the acute infarction. By earlier infarction is meant myocardial infarction diagnosed in hospital at least one month before admission to hospital. No patient has been included more than once. If a patient had more than one myocardial infarction during the trial period, only the first episode has been included.

In all patients the $Q / R$ ratios in $X, Y$, and $Z$ leads have been recorded in all orthogonal electrocardiograms. The $Q$ and $R$ wave amplitudes, respectively, have been measured by hand, using the PR segment as baseline. In cases where the wave amplitudes were seen to be particularly small, the amplitudes were increased by changing the calibration of the electrocardiogram analyser. A magnifying glass was used in all measurements which were performed on at least two different occasions in all cases. If there was any considerable discrepancy between the two results, they were repeated at least once more. In all cases with borderline ratios at least three measurements were performed. The criteria for pathological $Q / R$ ratios have been adopted from the work of Draper et al. (1964), also used by Naval, Cosma, and Pipberger (1967). This means that $Q / R$ ratios more than 0.21 in the $X$ lead, more than 0.22 in the $\mathrm{Y}$ lead, and less than $0 \cdot 10$ or more than $I \cdot 20$ in the $Z$ lead, in the absence of the WPW syndrome or left bundle-branch block, have been recorded as pathological $Q / R$ ratios caused by myocardial necrosis. $Q / R$ ratios more than $I \cdot 20$ have been discarded in cases with right bundlebranch block or in cases with signs of pure right ventricular hypertrophy. No case had congenital heart disease.

In the scalar electrocardiograms $R / S$ ratios more than $I \cdot O$ in $V_{I}$ and/or V2 have been recor- ded. $R$ waves less than $2 \mathrm{~mm}$ in $\mathrm{VI}_{\mathrm{I}}-\mathrm{V}_{3}$ have also been especially noted and defined as rudimentary $R$ waves in $V_{I}-V_{3}$ in the absence of left bundlebranch block or pulmonary emphysema.

\section{Results}

The material comprises 259 patients, of whom r9o were men and 69 women. The age and sex distribution are shown in Table I. The average age of the men was 60.0 years and of the women $67 \cdot 7$ years. The electrocardiographic localization of the infarction in the scalar electrocardiograms is summarized in Table 2, and so are the various equivocal changes. $A$ total of $124(65 \%)$ of the men and 38 of the women $(55 \%)$ had unequivocal signs of myocardial infarction in the scalar electrocardiogram according to accepted criteria (Lipman and Massie, 1965). In 7 of the men and 2 of the women the 12-lead electrocardiograms were within normal limits, despite typical case histories and SGOT rises. More cases,

TABLE I Age and sex distribution of 259 patients

\begin{tabular}{|c|c|c|}
\hline Age & Men & Women \\
\hline$<40 \mathrm{yr}$ & 6 & 0 \\
\hline $40-49$ yr & 27 & 4 \\
\hline $50-59$ yr & 56 & II \\
\hline $60-69$ yr & 65 & 22 \\
\hline $\begin{array}{l}>70 \\
\text { Average age }\end{array}$ & $\begin{array}{l}36 \\
60 \cdot 0 \mathrm{yr}\end{array}$ & $\begin{array}{l}32 \\
67 \cdot 7 \mathrm{yr}\end{array}$ \\
\hline
\end{tabular}

TABLE 2 Males and females Correlation between scalar electrocardiographic findings and clinical data

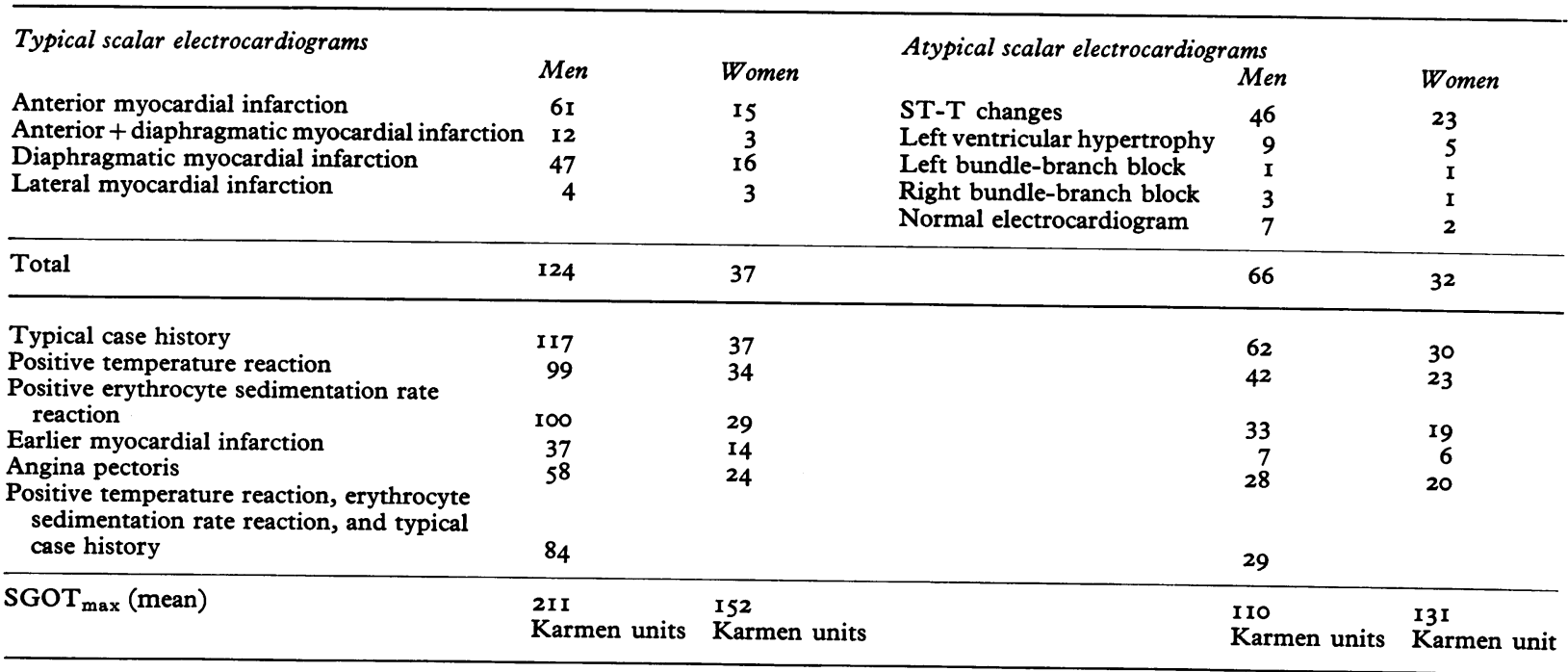


both male and female, with typical scalar electrocardiograms had positive temperature and erythrocyte sedimentation rate reactions than had those with atypical scalar electrocardiograms. The frequency of earlier myocardial infarction and angina pectoris was the same in both groups of both sexes.

Considering the scalar and orthogonal electrocardiograms together, the cases have been put into 4 subgroups (Table 3). Group I: Cases with typical scalar and typical orthogonal electrocardiograms; Group 2: Cases with atypical scalar, but typical orthogonal electrocardiograms; Group 3: Cases with atypical scalar and atypical orthogonal electrocardiograms; and Group 4: Cases with typical scalar electrocardiograms, but with atypical orthogonal electrocardiograms.

The ages in the different subgroups did not differ from the total material. However, the SGOT values were significantly higher in men with $Q$ wave infarctions (typical scalar) than in men with equivocal electrocardiographic signs, whether or not these cases had typical orthogonal electrocardiographic findings. In the small female group, cases with rypical scalar electrocardiograms had mean SGOT maximum values slightly higher than in the other groups.

In Table 4 the different orthogonal electrocardiographic diagnoses are summarized. In the same Table, 39 male and 15 female patients with equivocal scalar electrocardiograms and unequivocal orthogonal electrocardiograms are recorded. It is seen that the increase of diagnostic changes in the orthogonal electrocardiograms compared with the I2-lead electrocardiograms are mostly due to the addition of anterior and strictly posterior myocardial infarctions.

Strictly posterior myocardial infarctions
TABLE 3 Correlation between scalar electrocardiogram, orthogonal electrocardiogram, age, and serum transaminase (mean)

\begin{tabular}{|c|c|c|c|}
\hline \multirow{3}{*}{ Group I: } & \multirow{3}{*}{$\begin{array}{l}\text { No. of cases } \\
\text { Mean age } \\
\text { Age (range) }_{\text {SGOT }_{\max } \text { (mean) }}\end{array}$} & Men & Women \\
\hline & & I2I & \\
\hline & & $\begin{array}{l}59.9 \mathrm{yr} \\
33-80 \text { yr } \\
212 \text { Karmen units }\end{array}$ & $\begin{array}{l}68 \cdot 4 \text { yr } \\
48-81 \text { yr } \\
\text { I } 52 \text { Karmen units }\end{array}$ \\
\hline \multirow[t]{3}{*}{ Group 2: } & \multicolumn{3}{|c|}{ Atypical scalar but typical orthogonal electrocardiograms } \\
\hline & $\begin{array}{l}\text { No. of cases } \\
\text { Mean age }\end{array}$ & $\begin{array}{l}39 \\
62 \cdot 2 \mathrm{yr}\end{array}$ & $\begin{array}{l}13 \\
66 \cdot 1 \mathrm{yr}\end{array}$ \\
\hline & $\begin{array}{l}\text { Age (range) } \\
\text { SGOT }_{\max } \text { (mean) }\end{array}$ & $\begin{array}{l}34-90 \text { yr } \\
\text { I05 Karmen units }\end{array}$ & $\begin{array}{l}49-89 \mathrm{yr} \\
\text { I } 29 \text { Karmen units }\end{array}$ \\
\hline \multirow[t]{2}{*}{ Group 3: } & \multicolumn{3}{|c|}{ Atypical scalar and atypical orthogonal electrocardiograms } \\
\hline & $\begin{array}{l}\text { No. of cases } \\
\text { Mean age } \\
\text { Age (range) } \\
\text { SGOT }_{\max } \text { (mean) }\end{array}$ & $\begin{array}{l}27 \\
58 \cdot 0 \mathrm{yr} \\
40-85 \mathrm{yr} \\
\text { I } 16 \mathrm{Karmen} \text { units }\end{array}$ & $\begin{array}{l}19 \\
68 \cdot 2 \mathrm{yr} \\
41-85 \mathrm{yr} \\
\text { I } 32 \text { Karmen units }\end{array}$ \\
\hline \multirow[t]{2}{*}{ Group 4: } & \multicolumn{3}{|c|}{ Typical scalar electrocardiogram but atypical orthogonal electrocardiogram } \\
\hline & $\begin{array}{l}\text { No. of cases } \\
\text { Mean age } \\
\text { Age (range) }_{\text {SGOT }_{\max } \text { (mean) }}\end{array}$ & $\begin{array}{l}3 \\
52 \mathrm{yr} \\
37-68 \mathrm{yr} \\
\text { 161 Karmen units }\end{array}$ & o \\
\hline
\end{tabular}

were seen in 15 cases, i.e. 6 per cent. It is also seen that 3 cases with equivocal changes in the orthogonal electrocardiogram had unequivocal signs of myocardial infarction in the I2-lead electrocardiograms. Two had scalar diagnoses of anterior myocardial infarction and one diaphragmetic myocardial infarction. No woman had equivocal orthogonal electrocardiograms together with unequivocal scalar electrocardiogram.

$R / S$ ratios $>I$ in $V I$ and/or $V 2$ and rudimentary $R$ waves in $\mathrm{VI}_{\mathrm{I}}-\mathrm{V}_{3}$ in the scalar electrocardiograms are summarized in Table 5.

TABLE 4 Summary of orthogonal electrocardiogram findings

Typical orthogonal electrocardiograms (160) and (52)

Anterior myocardial infarction

Anterior + diaphragmatic myocardial infarction

Diaphragmatic myocardial infarction

Strictly posterior myocardial infarction

Lateral myocardial infarction

Diaphragmatic + posterior myocardial infarction

Diaphragmatic + lateral myocardial infarction

$\begin{array}{ll}\text { Men } & \text { Women } \\ 70 & 22 \\ 21 & 7 \\ 30 & 11 \\ 10 & 4 \\ 9 & 2 \\ 8 & 1 \\ 12 & 5\end{array}$

$\begin{array}{lll}\text { Atypical orthogonal electrocardiograms (30) and (I7) } & \\ \begin{array}{l}\text { Men } \\ \begin{array}{c}\text { Normal scalar and normal orthogonal } \\ \text { electrocardiograms }\end{array}\end{array} & \text { Women } \\ \begin{array}{c}\text { Normal orthogonal with atypical scalar } \\ \text { electrocardiogram }\end{array} & 4 & 2 \\ \begin{array}{c}\text { Atypical orthogonal electrocardiogram } \\ \text { with typical scalar electrocardiogram }\end{array} & 3^{\star} & \circ\end{array}$

Atypical scalar with typical orthogonal electrocardiograms (39) and (15)

Anterior myocardial infarction

Anterior + diaphragmatic myocardial infarction

Diaphragmatic myocardial infarction

Strictly posterior myocardial infarction

Lateral myocardial infarction

$\begin{array}{rl}18 & 9 \\ 1 & \\ 8 & \\ 10 & 5 \\ 2 & 1\end{array}$

* 2 cases with anterior myocardial infarction and $\mathrm{I}$ with diaphragmatic myocardial infarction. 
Twelve men and 2 women had an $R / S$ ratio $>I$ in $V I$ and V2. Five men and $I$ woman in this group had an orthogonal electrocardiographic diagnosis of diaphragmatic posterior or diaphragmatic lateral myocardial infarction. These 6 cases had typical Q wave infarctions in the 12-lead electrocardiogram. Five men and I woman with this sign had strictly posterior myocardial infarction according to the orthogonal electrocardiogram, while 2 men had lateral myocardial infarction. No case with this scalar sign had atypical or normal orthogonal electrocardiogram.

Of the 28 cases ( 22 male and 6 female) with an $R / S$ ratio more than $I$ in $V_{2}$ (but not in VI) (Table 5), 9 (8 male and I female) had unequivocal scalar signs of diaphragmatic myocardial infarction. In these 9 the orthogonal electrocardiogram pointed to an extension laterally or strictly posterior. In 12 cases (8 male and 4 female) with equivocal scalar electrocardiogram a diagnosis of strictly posterior or lateral myocardial infarction was made in the orthogonal electrocardiogram. Seven cases (6 male and I female) showed atypical findings in both 12-lead electrocardiogram and orthogonal electrocardiogram.

Rudimentary $\mathrm{R}$ waves in $\mathrm{VI}_{\mathbf{1}}-\mathrm{V}_{3}$ were recorded in 15 cases, of whom 14 had anterior myocardial infarction according to the orthogonal electrocardiogram (i.e. $Q / R$ ratios less than 0.10 ), while only I had equivocal signs of myocardial infarction in both 12-lead electrocardiogram and orthogonal electrocardiogram.

\section{Discussion}

Recent discussion of some simple electrocardiographic principles shows that one can never expect to diagnose all myocardial infarctions in the electrocardiograms (Erikssen, Müller, and Anderssen, 1970). Small subendocardial infarctions especially fail to produce QRS changes. Changes in the ST and $T$ waves alone are not diagnostic because they may be caused by other diseases, both noncoronary heart disease and extracardiac disorders. Moveover, infarction may be disguised by left bundle-branch block, though some authors think that myocardial infarction may be diagnosed as well in the presence of left bundle-branch block (Sodi-Pallares et al., 1963). Right bundle-branch block does not change the excitation process in the earlier part of the QRS, and therefore an anterior or diaphragmatic myocardial infarction should be diagnosable in its presence. The period from the 3 rd to the roth day after infarction
TABLE 5 Correlation between $R / S$ ratio $>1$ in $V 1$ and/or $V 2$ and rudimentary $R$-waves in V1-V3 with orthogonal electrocardiogram diagnosis

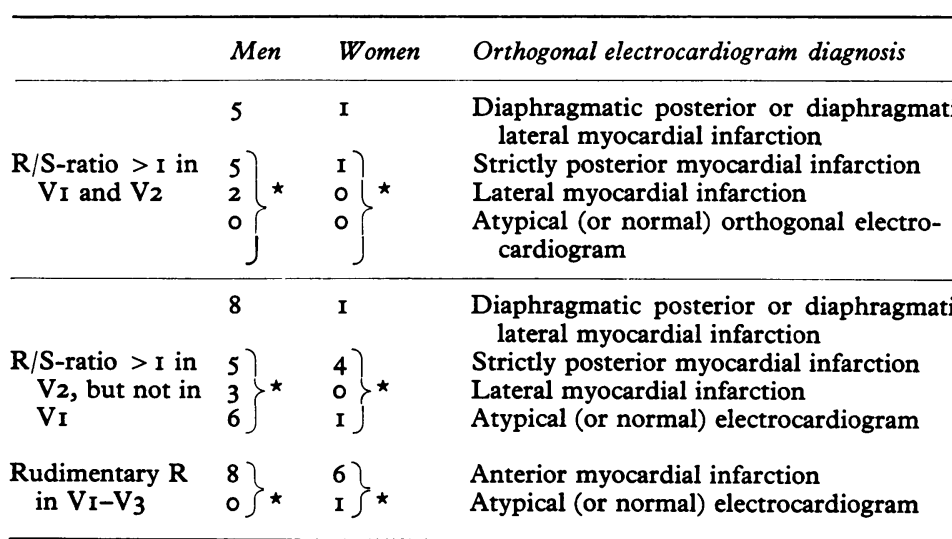

* Cases with equivocal i2-lead electrocardiograms.

poses a special problem to the electrocardiogram reader (Solomon and Shapiro, I966).

Transmural loss of myocardium produces pathological $Q$ waves in ordinary leads, giving rise to the common diagnostic changes of infarction, but infarctions that are not transmural may also create QS patterns. Mathur and Kumar (1965), in experimental work on dogs, stress that rudimentary $\mathbf{R}$ waves in the praecordial leads $V_{I}-V_{3}$ were uniformly related to anterior myocardial infarction, the changes in the excitation process being too small to give anything more than an obvious reduction in the $R$ wave instead of a fully developed $Q$ wave (or to insignificant $Q$ waves judged by the usual criteria?).

Depending on the spread of the excitation wave in the myocardium (Scher and Young, 1957), one might also assume that infarctions with special locations may change only the middle and/or the later part of the QRS complex. This is in agreement with, for instance, Abildskov and Boyle (1965) in their experimental work on dogs. In similar human cases one would especially expect changes in the $\mathbf{R}$ and $S$ waves. As myocardial infarction therefore probably may give rise to changes only in the $R$ wave and/or $S$ wave without simultaneous pathological $Q$ waves, it should be rational to use the $R / S$ or $Q / R$ ratios as signs of myocardial infarction instead of using $Q$ waves solely. (Whipple (1957) considers that pathological $Q$ waves have their pathological 'mirror image' $\mathbf{R}$ waves on the opposite side of the body and vice versa). In this way it should be possible to recognize both the usual changes in the early part of the QRS ( $Q$ wave 
sattern in ordinary scalar reading) and the nore subtle changes which mainly affect the reight of the $R$ waves.

The importance of using $Q / R$ ratios in the liagnosis of myocardial infarction is stressed Jy Naval et al. (1967), and their conclusions orm the basis for this work. They state that Diagnostic recognition rates of $Q / R$ ratios :xceeded those of $\mathrm{Q}$-wave duration and $\mathrm{Q}$ vave amplitude by a wide margin. Sixty-two ases or twenty-nine per cent would have been nissed without measuring the $\mathrm{Q} / \mathrm{R}$-ratio. The $\mathrm{Q}$-wave duration was found to be the inly abnormality in five cases, or two per cent if the cases...'.

Naval et al. used a digital computer for all neasurements and evaluations. In this work 11 waves were measured by hand, using the ' $R$ segment as baseline to determine the mplitudes, and a relatively large statistical rror may of course be introduced. In all ases, therefore, measurements were perormed on at least two different occasions nd repeated if there was any considerable iscrepancy between the two results. It is hought, therefore, that they are valid from a tatistical point of view despite the common bserver variation in the interpretation of lectrocardiograms.

As electrocardiographic patterns of myoardial infarction may be caused by other iseases, only cases with recent myocardial ufarctions have been included. The diagnosic score of the 12-lead electrocardiogram in ais work is low, 65 per cent in male and 55 er cent in female patients using accepted zalar criteria.

The SGOT values in the men with $Q$ wave atterns were significantly higher than in men ith atypical scalar findings, which may, erhaps, be taken as indicating more extensive $\checkmark$ wave myocardial infarctions'. In the naller female group, however, no such atistical difference in the SGOT values was und. In both the male and female groups a igher percentage of cases with ' $Q$ wave inIrctions' had positive erythrocyte sedimenttion rate and/or temperature reactions than ises with atypical scalar electrocardiograms. : one assumes that the largest myocardial farctions on an average give rise to the eaviest reactions in the body this may also be ken as a sign of larger infarctions with $Q$ ave patterns than with atypical electrocardioams. The advantage of using $Q / R$ ratios is in the possibility of diagnosing infarctions hich fail to create detectable changes in dinary scalar readings. Our results seem to infirm such a view. Nevertheless, scalar gns not commonly used may be of import- ance in the diagnosis of myocardial infarctions. Thirty-nine of the men and 15 of the women had diagnostic orthogonal electrocardiographic changes (Table 3 ) in the presence of equivocal scalar findings in the 12-lead electrocardiograms. If the criteria of Perloff (1964) had been used ( $R / S$ ratio $>I$ in VI and/or V2) 20 cases would have been transferred from the atypical to the typical group, including all cases with strictly posterior myocardial infarctions and 5 cases with lateral myocardial infarctions. However, using R/S ratio $>\mathrm{I}$ in $\mathrm{V} 2$ alone as the sign of lateral or strictly posterior myocardial infarction would have included 7 cases (Table 5), in whom both the orthogonal and the scalar electrocardiograms were atypical. In 25 per cent of these cases (Table 5), therefore, this sign was of doubtful value.

In 14 of 15 cases with rudimentary $R$ waves in $\mathrm{VI}_{\mathrm{I}}-\mathrm{V}_{3}$ the orthogonal electrocardiograms pointed to anterior myocardial infarction. This is in agreement with Mathur and Kumar's statement above.

Including these $34(20+14)$ cases among the cases with typical 12 lead electrocardiograms would increase the overall recognition rate from $16 \mathrm{I} / 259(62 \%)$ to $195 / 259(75 \%)$. As 54 cases (39 men and 15 women: Table 3 ) had typical orthogonal electrocardiograms in the presence of atypical I2-lead electrocardiograms we see that a further 20 cases still had orthogonal criteria of myocardial infarction.

Using the orthogonal criteria solely would give a recognition rate of $212 / 259(82 \%)$. This means that 20 per cent $(82$ less $62 \%$ ) would have been missed using ordinary scalar reading instead of this particular orthogonal reading. Only 7 per cent, however, would have been missed if the r2-lead reading had included the criteria of $R / S$ ratio in $V_{I}$ and $V_{2}$ and rudimentary $R$ waves in $V_{I}-V_{3}$.

These findings, of course, do not mean that orthogonal electrocardiograms are devoid of errors. The same theoretical obstacles occur as in the 12 lead scalar electrocardiograms. The main advantages of the technique are the strict diagnostic criteria, and the fact that an electrocardiogram with only 3 leads is much easier to interpret.

The $Q / R$ ratios used may be questioned, but the evidence for them seems convincing (Draper et al., 1964) despite possible racial differences.

It might be presumed that the r2-lead electrocardiogram should give more information than an electrocardiogram using but 3 leads. If so, diagnostic changes seen in the 12lead electrocardiogram would be missed in the orthogonal electrocardiogram. However, 
this was seen in only 3 cases: 2 cases with anterior and I with diaphragmatic myocardial infarction. Moreover, it has been shown that all the information obtained in the ordinary I2-lead electrocardiogram may be found in the orthogonal electrocardiogram (Pipberger et al., I967; Rübesamen and Giegler, I969), by projecting the $\mathrm{X}, \mathrm{Y}$, and $\mathrm{Z}$ complexes onto the conventional electrocardiogram axes, I, II, III, aVF, and so forth. This applies to all but local apical potential variations, according to Grant (1957), and is consistent with current electrocardiographic theory.

This material is biased both as regards case histories and electrocardiograms because all patients who died during the first 24 hours were included. This was done in order to obtain at least one orthogonal and one 12-lead electrocardiogram taken by an experienced electrocardiogram technician and to secure the diagnosis with pathological SGOT values. A large proportion of cases dying within the first 24 hours had diagnostic I2-lead electrocardiograms. This, however, does not alter the conclusion that orthogonal electrocardiograms are of value in the diagnosis of recent myocardial infarction. The $Q / R$ ratios obtained from the orthogonal electrocardiogram may be of particular value, in conformity with the findings of Naval and his co-workers (I967).

\section{References}

Abildskov, J. A., and Boyle, R. S. (1965). Further studies of the electrocardiographic effects of experimental myocardial lesions. American Heart fournal, 69, 49.

Draper, H. W., Peffer, Catherine J., Stallmann, F. W., Littmann, D., and Pipberger, H. V. (1964). The corrected orthogonal electrocardiogram and vectorcardiogram in 510 normal men (Frank lead system). Circulation, 30, 853.

Erikssen, J., Müller, C., and Anderssen, J. N. (1970). Atypical case histories and electrocardiograms in myocardial infarcts. Acta Medica Scandinavica, I88, 95.

Frank, E. (1956). An accurate, clinically practical system for spatial vectorcardiography. Circulation, I3, 737.

Grant, R. P. (1957). Clinical Electrocardiography, the Spatial Vector Approach. Blakiston, New York.

Lipman, B. S., and Massie, E. (1965). Clinical Scalar Electrocardiography, 5th ed. Year Book Medical Publishers, Chicago.

Mathur, K. S., and Kumar, V. (1965). An experimental study of anterior myocardial infarction and correlation of electrocardiographic changes with localization on infarct. Fournal of the Indian Medical Association, 44, 56.

Naval, I. A., Cosma, J., and Pipberger, H. V. (1967). Reevaluation of the Q-wave in the electrocardiographic diagnosis of myocardial infarction. Medical Annals of the District of Columbia, 36, 349.

Perloff, J. K. (1964). The recognition of strictly posterior myocardial infarction by conventional scalar electrocardiography. Circulation, 30, 706.

Pipberger, H. V., Goldman, M. J., Littmann, D., Murphy, G. P., Cosma, J., and Snyder, J. R, (1967). Correlations of the orthogonal electrocardiogram and vectorcardiogram with constitutional variables in 518 normal men. Circulation, 35 . 536.

Rübesamen, M., and Giegler, J. (1969). Der Herzinfarkt im korrigierten orthogonalen Elektrokardiogram. Zeitschrift für Kreislaufforschung, 58, 223.

Scher, A. M., and Young, A. C. (1957). Ventricular depolarization and the genesis of QRS. Annals of the New York Academy of Sciences, 67, 768.

Sodi-Pallares, D., Cisneros, F., Medrano, G. A., Bisteni, A., Testelli, M. R., and de Micheli, A, (1963). Electrocardiographic diagnosis of myocardial infarction in the presence of bundle branch block (right and left), ventricular premature beats and Wolff-Parkinson-White syndrome. Progress in Cardiovascular Disease, 6, 107.

Solomon, R. B., and Shapiro, H. H. (1966). The electrocardiographic 'intermediate phase' of an acute myocardial infarction. American Heart fournal, 71, 582.

Whipple, G. H. (1957). Current concepts in electrocardiography: a critique of the unipolar approach to interpretation. Medical Clinics of North America, 41, II93.

Requests for reprints to Dr. Carsten Müller, Rikshospitalet, Pilestredet 32, Oslo I, Norway. 